\title{
Synthesis of N'-(2-
}

\section{Methoxybenzylidene)-4-Hydroxy}

Benzohydrazide and N'-(4-

\section{Nitrobenzylidene)-4-Hydroxy \\ Benzohydrazide, in Silico Study and Antibacterial Activity by Isnaeni Isnaeni}

Submission date: 27-Mar-2019 10:54AM (UTC+0800)

Submission ID: 1100520798

File name:y_Benzohydrazide,_in_Silico_Study_and_Antibacterial_Activity.pdf (490.82K)

Word count: 2942

Character count: 17504 
Research Article

\title{
Synthesis of N'-(2-Methoxybenzylidene)-4-Hydroxy Benzohydrazide and N'-(4-Nitrobenzylidene)-4-Hydroxy Benzohydrazide, in Silico Study and Antibacterial Activity
}

\author{
Suzana, Isnaeni,Tutuk Budiati* \\ Faculty of Pharmacy Airlangga University, Dharmawangsa Dalam Street, Surabaya 60286-Indonesia.
}

Available Online: $25^{\text {th }}$ January, 2017

\begin{abstract}
In this study, synthesized N'-(2-methoxybenzylidene)-4-hydroxybenzohydrazide and N'-(4-nitrobenzylidene)-4hydroxybenzohydrazide in two step reaction by using methylparaben as starting material has been performed. Methylparaben was treated with hydrazine hydrate to obtain 4-hydroxybenzohydrazide. The reaction was carried out by microwave irradiation resulting $91 \%$ yield. The obtained compound was then reactal with 2-methoxbenzaldehyde or 4nitrobenzaldehyde to accomplish the target molecule, $\mathrm{N}^{\prime}$-(2-methoxybenzylidene)-4-hydroxybenzohydrazide and $\mathrm{N}^{\prime}-(4-$ nitrobenzylidene)-4-hydroxybenzohydrazide in $55 \%$ and $72 \%$ yield respectively. Identification of $\mathrm{N}^{\prime}-(2-$ me(10xybenzylidene)-4-hydroxy benzo hydrazide and N'-(4-nitrobenzylidene)-4-hydroxybenzohidroksida was performed by FT-IR, MS, 'H-NMR, and ${ }^{13} \mathrm{C}-\mathrm{NMR}$ spectroscopy. In silico study was done with receptor pdb $1 \mathrm{C} 14$. The N'-(4nitrobenzylidene)-4-hydroxybenzohydrazide exhibited antimicrobial activity against Escherichia coli $(\mathrm{MIC}=31.3 \mathrm{ppm})$, Bacillus subtilis $(\mathrm{MIC}=500 \mathrm{ppm})$. Antimicrobial activity of $\mathrm{N}^{\prime}-(2$-methoxybenzylidene)-4-hydroxybenzohydrazide against Bacillus subtilis $(\mathrm{MIC}=31.3 \mathrm{ppm})$ and $\mathrm{MIC}=500 \mathrm{ppm}$ against Escherichia coli.
\end{abstract}

Keywords: Synthesis, N'-Benzylidene-4-hydroxybenzohydrazide derivatives, microwave, antibacterial.

\section{INTRODUCTION}

New drugs invention and development is crucial in the pharmaceutical industry. The application of conventional methods in developing new drugs such as through organic reactions which require high temperature has been widely practiced. Traditional heater equipment which are commonly used are sand-bath, oil-bath, and heating mantle These techniques take much time to react the samples and may cause temperature differences on the samples. Moreover, heated reaction flask surface may cause localized overheating which results products, reagents, and substrate decomposition in prolonged heating. Therefore, new reaction methods which are expected to be able to perform quicker synthesis with higher product percentage and quality should be proposed. One of new synthesis methods is conducted by microwave irradiation. This technique is applied in new drugs development ${ }^{1-3}$. Hydrazide derivatives are widely used in new drug development for its biological activity and various clinical applications such as anticancer ${ }^{4}$, antitumor ${ }^{5}$, antimicrobial ${ }^{6}$, antifungal ${ }^{7,8}$, antiHIV ${ }^{9}$, and antituberculosis ${ }^{10}$. In some literature, it is mentioned that hydrazide derivatives have pharmacological activities (i.e. anticancer, anticonvulsant, antiinflammation, antibacterial, and antioxidant) are related to $-\mathrm{CONHN}=\mathrm{CN}$ functional group in its molecular structure $^{10}$. Although hydrazide derivatives can be synthesized with conventional ${ }^{11}$ and microwave irradiation methods in this research, we attempt to conduct synthesis reaction by applying microwave irradiation. This method is chosen because it takes shorter time and it's able to result higher percentage product. The products are more ecofriendly because no toxic solvents are used in this process. Moreover, optimization of 4-hydroxybenzohydrazide derivatives were using microwave irradiation reaction method has not been conducted. Based on the background explained above, the problem proposed in this research is whether microwave irradiation can be used to synthesize 4-hydroxybenzohydrazide compound and its derivatives. Synthesis of 4-hydroxybenzohydrazide derivatives used methyl paraben as starting material. This research is expected to be able to provide new understanding of condensation reaction through the application of microwave irradiation to synthesize 4hydroxybenzohydra11 e derivatives. The compounds are tested antibacterial activity against Bacillus subtilis (Gram positive) and Escherichia coli (Gram negative). The scheme of synthesis reaction is presented in Figure 1.

\section{MATERIALS AND METHODS}

All chemicals were used in this study from commercial sources. Methyl paraben, hydrazine hydrate, 2methoxybenzaldehyde, 4-nitrobenzaldehide ethanol $95 \%$, chloroform, ethyl acetate, acetone, hexane, $\mathrm{KBr}$, silica gel $60 \mathrm{GF}_{254}$ were purchased from Merck. Glassware commonly used in the chemical synthesis laboratories, Sanyo microwave EM-S 400 Watt, Spectrophotometer

*Author for Correspondence: suzanarushadi@yahoo.com 
Buck Scientific IR M-500, FT-NMR spectrometer JEOL ECS-400.

Preparation of 4-hydroxybenzohydrazide (I) with microwave irradiation ${ }^{12,13}$

Methyl paraben $(10 \mathrm{mmol})$ and hydrazine hydrate (50 $\mathrm{mmol}$ ) were stirred until homogeneous. The mixture was put in the microwave on $160 \sqrt{5 \mathrm{tt}}$ power for 2-8 minutes while stirring every 2 minutes. The progress of the reaction was monitored by TLC. The mixture was cooled to room 1 mperature and then added $20-30 \mathrm{ml}$ of ice water, filtered, washed with ethanol. Crystals were recrystal 1 zed with absolute ethanol. The purity tests were done by melting point and thin layer chromatography (TLC) using 1 hree different eluents Identifications were carried out by FT- IR, and ${ }^{1} \mathrm{H}-\mathrm{NMR}$ spectroscopy.

Preparation of $\quad N^{\prime}$-(2-methoxybenzylidene)-4hydroxybenzohydrazide and $N$ '-(4-nitrobenzylidene)-4hydroxybenzohydrazide $e^{12,13}$

4-Hydroxybenzohydrazide $(10 \mathrm{mmol})$ and benzaldehyde $(20 \mathrm{mmol})$ were dissolved in ethanol $(12 \mathrm{ml})$. Ethanol was evaporated until exhausted. The mixture was put in the microwave on 320 Watt power for 2 minutes (for synthesis IIb), 15 on 160 Watt power for 4 minutes (for synthesis IIa). The mixture was cooled to room temperature, then added to 120-30 $\mathrm{ml}$ of ice water, filtered, washed with ethanol. Crystals were crystallized 1 ith absolute ethanol. The purity tests were done using melting point and thin layer chromatography using $17 \mathrm{ee}$ different eluents. Identifications were carried out by FT-IR, MS, ${ }^{1} \mathrm{H}-\mathrm{NMR}$, and ${ }^{13} \mathrm{C}-\mathrm{NMR}$ spectroscopy.

14 ibacterial Activity

Antibacterial activity was done by well diffusion method $^{14-16}$. In this method, The wells are filled with test compounds. Petri plate was labeled with the name of the 2 lture, sample and standard at the bottom of the plate. Inoculums were standardized by adjusting the turbidit $2 \mathrm{of}$ the culture according to McFarland standards. The standardized inoculums was prepared in the petri plates. Then sterile agar medium and suspension of microbial cultures were poured into a petri dish aseptically. Petri dishes are left at room tempera 8 e for 15 minutes and then incubated $37^{\circ} \mathrm{C}$ for 24 hours ${ }^{17}$. After incubation at $37^{\circ} \mathrm{C}$ for 9 hours, the diameter of the zone inhibition was measured The inhibitory activity of DMSO was also employed as a negative control. Positive control used Nifuroxazide 31.3 $\mathrm{ppm}$. The te 10 compounds were evaluated for their antibacterial activity against Escherichia coli (ATCC 25922) and Bacillus subtilis (ATCC 6633) ${ }^{18}$

\section{RESULTS AND DISCUSSION}

Synthesis of 4-hydroxybenzohydrazide derivatives using condensation reaction were carried in two reaction phases. The first phase was conducted reaction methyl paraben with hydrazine hydrate with microwave irradiation 161 Watt power for 2-8 minutes to produce 4hydroxybenzohydrazide. It was done by the nucleophilic substitution reaction ${ }^{11}$. The second phase was conducted to produce 4-hydroxybenzohydrazide derivatives using the condensation reaction method. This method was chosen for its practicality and not requiring toxic solvent. Besides, the method took a relatively short time (about 8 minutes) The reaction was carried out without toxic solvent Therefore, this reaction conformed to eco-chemistry because lacking of toxic solvent and energy saving ${ }^{19,20} .4$ Hydroxybenzohydrazide derivatives were synthesized by reacting 4-hydroxy benzohydrazide and 2methoxybenzaldehyde or 4-nitrobenzaldehyde. Ethanol was used as solvent, then evaporated to run out.

Characterization of 4-hydroxybenzohydrazide (I) $)^{21,22}$

Obtained in $91 \%$ yield as white needle-shaped crystals The result of purity test was conducted using thin-layer chromatography indicated one stone. Three of eluents were chloroform:ethyl acetate (1:1), chloroform:ad 1 on (1:2) and aceton ethyl acetate $(2: 1), \mathrm{mp} \cdot 255-256^{\circ} \mathrm{C}$. IR ( $\mathrm{KBr}$ in $\left.\mathrm{cm}^{-1}\right): 1620$ (-C $=\mathrm{O}$ amide), 3318 (-OH phenolic), 1590 and $1467(-\mathrm{C}=\mathrm{C}-$ aromatic $), 1354(\mathrm{C}-\mathrm{N}), 3005\left(\mathrm{Csp}^{2}-\mathrm{H}\right), 850$ (para disubstitution on be $13 \mathrm{na}), 3197\left(-\mathrm{NH}_{2}\right)$. 1H-NMR (DMSO-d $\left.\mathrm{d}_{6} \delta 1 \mathrm{pm}\right): 6.74-6.72\left(\mathrm{~d}, J=8.4 \mathrm{~Hz}, 2 \mathrm{H}, \mathrm{C}_{6} \mathrm{H}_{4}-{ }^{-}\right.$), 7.65-7.62 (d, J=9.2 Hz, 2.H, $\left.\mathrm{C}_{6} \mathrm{H}_{4}-\right), 9.89(\mathrm{~s}, 1 \mathrm{H}, \mathrm{OH}), 9.44$ (s, $1 \mathrm{H}, \mathrm{NH}), 4.32\left(\mathrm{~s}, 2 \mathrm{H}, \mathrm{NH}_{2}\right)$

Characterization of $N^{\prime}$-(2-methoxybenzylidene)-4hydroxybenzohydrazide $(I I a)^{21,22}$

Obtained in $55 \%$ yield as white needle-shaped crystals The result of purity test was conducted using thin-lay 1 chromatography indicated one stain, m.p. $229-230{ }^{\circ} \mathrm{C}$. IR $\left(\mathrm{KBr}\right.$ in $\left.\mathrm{cm}^{-1}\right): 1606(-\mathrm{C}=\mathrm{O}$ amide), 3090 (-OH phenolic), $1508(-\mathrm{C}=\mathrm{C}-$ aromatic $), 1557(-\mathrm{NH}), 1359(\mathrm{C}-\mathrm{N}), 2941$ $\left(\mathrm{Csp}^{3}-\mathrm{H}\right), 841$ (para disubstitution on benzen 1) 1606 $(\mathrm{C}=\mathrm{N}), 1254$ (phenilalkil eter). $\left[\mathrm{M}^{+}\right]=270 .{ }^{1} \mathrm{H}-\mathrm{NMR}$ $\left(\right.$ DMSO-d $\left._{6}, \delta, \mathrm{ppm}\right): 11.61(\mathrm{~s}, 1 \mathrm{H}, \mathrm{OH}), 10.08(\mathrm{~s}, 1 \mathrm{H}, \mathrm{NH})$, $8.74(\mathrm{~s}, 1 \mathrm{H}, \mathrm{HC}=\mathrm{N}), 6.82-6,79(4 \mathrm{~J}=8.4 \mathrm{~Hz}, 2 \mathrm{H}$ from aromatic ring), 6.99-6.95 (t, J=8 Hz, $1 \mathrm{H}$ from aromatic ring), 7.06-7.04 (d, J=8.8 Hz, $1 \mathrm{H}$ from aromatic ring), 18 - $7.34(\mathrm{t}, \mathrm{J}=7.2 \mathrm{~Hz}, 1 \mathrm{H}$ fron 12 omatic ring), 7.78-7.76 (d, $\mathrm{J}=8.4 \mathrm{~Hz}, 1 \mathrm{H}$ from aromatic ring), 7.82-7.80 (d, $\mathrm{J}=8 \mathrm{~Hz}$, $2 \mathrm{H}$ from aromatic ring), $3.90\left(\mathrm{~s}, 3 \mathrm{H}, \mathrm{OCH}_{3}\right),{ }^{13} \mathrm{C}-\mathrm{NMR}$ (DMSO-d $\left.\mathrm{d}_{6}, \delta, \mathrm{ppm}\right): 163.05,161.16,158.13,142.71$, $131.84,130.18,125.93$ (2C), 124.34, 123.02, 121.25, 115.50 (2C), $112.31,56.17$.

Characterization of $\quad N^{\prime}$-(4-nitrobenzylidene)-4hydroxybenzohydrazide $(I I b)^{21,22}$

Obtained in $72 \%$ yield as yellow needle-shaped crystals The result of purity test was conducted using thin-lay 1 chromatography indicated one stain, m.p. $289-290^{\circ} \mathrm{C}$. IR ( $\mathrm{KBr}$ in $\left.\mathrm{cm}^{-1}\right): 1657$ (-C=O amide), 3467 (-OH phenolic), $1581(-\mathrm{C}=\mathrm{C}-$ aromatic $), 3168(-\mathrm{NH}), 3340\left(\mathrm{NH}_{2}\right), 1341$ $(\mathrm{C}-\mathrm{N}), 846$ (para disubstitui on on benzena), $1606(\mathrm{C}=\mathrm{N})$ $1512(\mathrm{~N}=\mathrm{O}) .\left[\mathrm{M}^{+}\right]=285 .{ }^{1} \mathrm{H}-\mathrm{NMR}\left(\mathrm{DMSO}-\mathrm{d}_{6}, \delta, \mathrm{ppm}\right)$ : $11.90(\mathrm{~s}, 13 \mathrm{OH}), 10.16(\mathrm{~s}, 1 \mathrm{H}, \mathrm{NH}), 8.47(\mathrm{~s}, 1 \mathrm{H}, \mathrm{HC}=\mathrm{N})$, $6.85-6,83$ (d, $\mathrm{J}=8.8 \mathrm{~Hz}, 2 \mathrm{H}$ from aromatic ring), 7.80-7.78 $(\mathrm{d}, \mathrm{J}=8.8 \mathrm{~Hz}, 2 \mathrm{H}$ from aromatic $16 \mathrm{~g}), 7.92-7.90(\mathrm{~d}$, $\mathrm{J}=8.4 \mathrm{~Hz}, 2 \mathrm{H}$ from aromatic ring), $8.25-8.22(\mathrm{~d}, \mathrm{~J}=8.8 \mathrm{~Hz}$, $2 \mathrm{H}$ from aromatic ring). ${ }^{13} \mathrm{C}-\mathrm{NMR}$ (DMSO- $\mathrm{d}_{6}, \delta$, ppm): $163.47,161.51,148.12,144.73,141.42,130.43$ (2C), $128.33,124.57$ (2C), 123.99 (2C), 115.61 (2C).

In Silico Study

To estimate the antimicrobial activity of derivatives 14 hydroxybenzohydrazide, in silico study was done with receptor pdb 1C14 program MVD 5.0 (Mollegro Virtual Docker). $1 \mathrm{C} 14$ is a receptor model of inhibitor triclosan, 


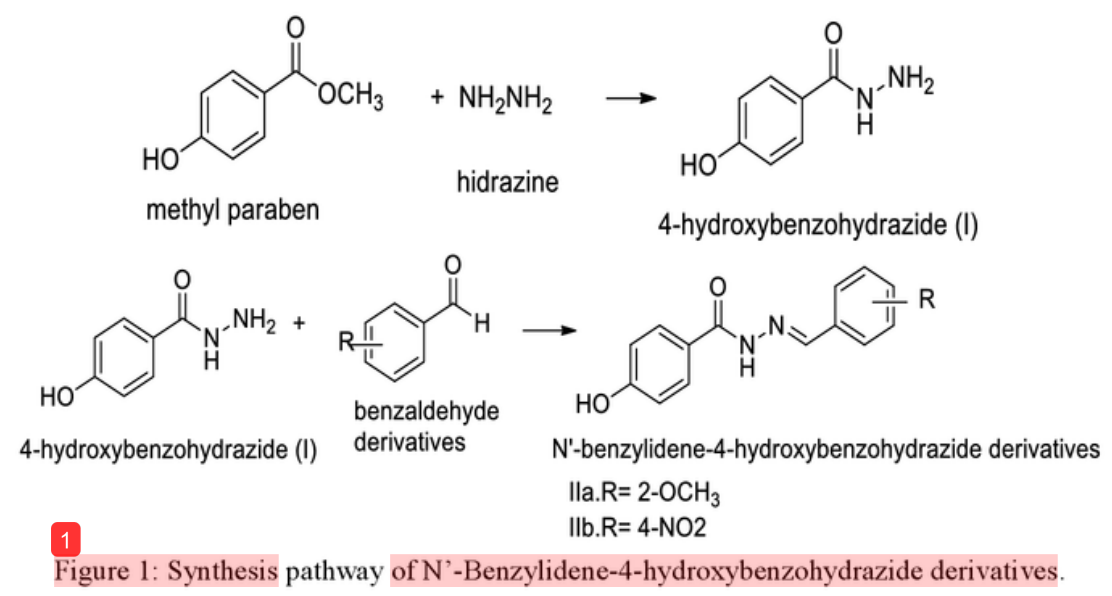

Table 1: Result of docking molecule methyl paraben, N'-(2-methoxybenzylidene)-4-hydroxy

benzohydrazide and N'-(4-nitroben 1 lidene-4hydroxybenzohydrazide with receptor pdb. 1C14 program MVD 5.0 (Mollegro Virtual Docker).

\begin{tabular}{lll}
\hline Compounds & $\begin{array}{l}\text { Rerank } \\
(\mathrm{kcal} / \mathrm{mol})\end{array}$ & Score \\
\hline & -66.498 \\
\end{tabular}

Methyl paraben

$$
\text { NO }
$$

4-hydroxybenzohydrazide (I)<smiles>O=C(N/N=C/c1ccc(OCCCCO)o1)c1ccc(O)cc1</smiles>

Nifuroxazide

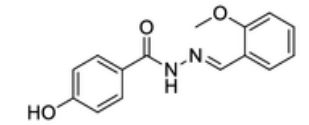

$-108.675$

N'-(2-methoxybenzylidene)-4-

hydroxybenzohydrazide (IIa)

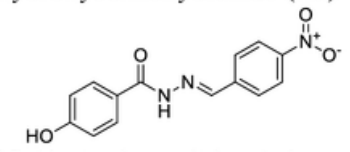

$-106.264$

N'-(4-nitrobenzylidene)-4-

hydroxybenzo hydrazide (IIb)

with the ligand code NAD. Based on the rerank score it was found that the target compounds exhibited a greater antimicrobial activity than methyl paraben ${ }^{24}$.

Antibacterial .7ctivity

The synthetic compounds were evaluated for antibacterial activity against Gram positive (Bacillus subtilis) and Gram negative (Escherichia coli). Antibacterial activities against
Escherichia coli of the compounds as well as reference drug are summarized in $\mathrm{Tab} 1$. The results indicated that N'-(2-methoxybenzylidene)-4-hydroxybenzohydrazide and $\mathrm{N}^{\prime}$-(4-nitrobenzylidene) -4-hydroxybenzohydrazide have had activities against $E$. coli. Results of minimal inhibitory concentration (MIC) of N'-(2methoxybenzylidene)-4-hydroxyben zohydrazide was 500 ppm and N'-(4-nitrobenzylidene)-4hydroxybenzohydrazide was $31.3 \mathrm{ppm}$. N'-(4nitrobenzylidene)-4-hydroxybenzohydrazide has MIC against $E$. coli (Gram negative) bigger than N'-(2methoxybenzylidene)-4-hydroxybenzohydrazide.

Antibacterial activities against Bacillus subtilis of the compounds as well as reference drug are summarized in Table 2 The results indicated that N'-(2methoxybenzylidene)-4-hydroxybenzohydrazide and N'(4-nitrobenzylidene)-4-hydroxybenzohydrazide had activitied against Bacillus subtilis. Results of minimal inhibitory concentration (MIC) of N'-(2methoxybenzylidene)-4-hydroxybenzohydrazide was 31.3 ppm and N'-(4-nitrobenzy lidene)-4hydroxybenzohydrazide was 500 ppm. N'-(2methoxybenzylidene)-4-hydroxy benzohydrazide has MIC against B. subtilis (Gram positive) bigger than $\mathrm{N}$-(4nitrobenzylidene)-4-hydroxybenzohydrazide. The antibacterial activity of the target compounds due to the phenolic group $\left(\mathrm{HO}-\mathrm{C}_{6} \mathrm{H}_{5}-\right)^{25}$ and the azometin group ($\mathrm{HN}-\mathrm{N}=\mathrm{CH}-)^{26}$. Variations of the target compound antibacterial activity against different bacteria (Gram positive / Gram negative) is influenced by electronic, steric, and lipophilicity of compounds. In silico test lipophilicity factors not included, so it can give different results ${ }^{24}$.

\section{CONCLUSION}

It can be concluded that N'-2-methoxybenzylidene-4hydroxybenzohydrazide and its derivatives can be synthesized from the methyl paraben as starting material by microwave irradiation (160-320 Watt power for 2-8 minutes). The yields were obtained between $55-72 \%$. The preliminary biological tests indicated that $\mathrm{N}^{\prime}-(4-$ nitrobenzylidene)-4-hydroxybenzohydrazide has effective activity against Escherichia coli $(\mathrm{MIC}=31.3 \mathrm{ppm})$, and 
Suzana et al. / Synthesis of N'-(2-Methoxybenzylidene) ...

\begin{tabular}{|c|c|c|c|c|c|c|c|c|}
\hline \multirow[t]{3}{*}{ Compound } & \multicolumn{6}{|c|}{ Inhibition zone $(\mathrm{mm})$} & \multirow{3}{*}{$\begin{array}{l}\text { Amoxi } \\
\text { cillin }\end{array}$} & \multirow{3}{*}{$\begin{array}{l}\text { Control } \\
\text { negative }\end{array}$} \\
\hline & \multicolumn{6}{|c|}{ Concentration $(\mathrm{ppm})$} & & \\
\hline & 31,3 & 62,5 & 125 & 250 & 500 & 1000 & & \\
\hline I & - & - & - & - & - & - & $14.5 \pm 0.67$ & - \\
\hline IIa & - & - & - & - & - & $11.5 \pm 0.50$ & $14.0 \pm 0.50$ & - \\
\hline IIb & - & $10.0 \pm 0.33$ & $12.0 \pm 0.50$ & $14.5 \pm 0.67$ & $16.5 \pm 0.67$ & $13.0 \pm 0.50$ & $14.0 \pm 0.67$ & - \\
\hline
\end{tabular}

(-) No inhibition zone, $\mathrm{n}=3$ replications.

Table 3: Antibacterial activity against Bacillus subtilis of the test compounds.

\begin{tabular}{|c|c|c|c|c|c|c|c|c|}
\hline \multirow[t]{3}{*}{ Compound } & \multicolumn{6}{|c|}{ Inhibition zone $(\mathrm{mm})$} & \multirow{3}{*}{$\begin{array}{l}\text { Amoxi } \\
\text { cillin }\end{array}$} & \multirow{3}{*}{$\begin{array}{l}\text { Control } \\
\text { negative }\end{array}$} \\
\hline & \multicolumn{6}{|c|}{ Concentration $(\mathrm{ppm})$} & & \\
\hline & 31,3 & 62,5 & 125 & 250 & 500 & 1000 & & \\
\hline I & - & - & - & - & $12.0 \pm 0.33$ & $10.0 \pm 0.50$ & $14.5 \pm 0,67$ & - \\
\hline IIa & - & $9.5 \pm 0.33$ & $9.5 \pm 0.50$ & $9.5 \pm 0.33$ & $11.0 \pm 0.67$ & $11.3 \pm 0.40$ & $14.0 \pm 0,67$ & - \\
\hline $\mathrm{IIb}$ & - & - & - & - & - & $9.5 \pm 0.33$ & $14.0 \pm 0,50$ & - \\
\hline
\end{tabular}

(-) No inhibition zone, $\mathrm{n}=3$ replications.

N'-(2-methoxybenzylidene)-4-hydroxybenzohydrazide has effective activity against Bacillus subtilis $(\mathrm{MIC}=31.3$ $\mathrm{ppm}$ ).

\section{CKNOWLEDGMENT}

This research was financially funded by Indonesian Directorate General of Higher Education (DGHE) or DIKTI through Penelitian Unggulan Perguruan Tinggi's scheme of 2016 .

\section{REFERENCES}

1. Kappe O. Microwave-enhanced chemistry-anything technology revolutionizing organic synthesis and drug discovery 2004.

2. Mavandadi F, Lidstrom P. Microwave-assisted chemistry in drug discovery. Current Topics in Medicinal Chemistry 2004; 4: 773-92.

3. Suthakaran R, Kavimani S, Venkappayya D, Jayasree P, Deepthi V, Tehseen F, Suganthi K. Microwave assisted rapid synthesis and anti-microbial activity of 4-oxothiazolidine derivatives. Rasayan J. Chem. 2008; 1: $30-8$.

4. Al-Abdullah ES. Synthesis and anticancer activity of some novel tetralin-6-yl-pyrazoline, 2thioxopyrimidine, 2-oxopyridine, 2-thioxo-pyridine and 2-iminopyridine derivatives. Molecules 2011; 16 : 3410-9.

5. Mohareb RM, Mohamed AA. The reaction of cyanoacetylhydrazine with w-bromo-(4methyl)acetophenone: Synthesis of heterocyclic derivatives with antitumor activity. Molecules 2010; 15: 3602-17.

6. Manivel P, Mohana RS, Kumar SR, Nawazkhan F, Synthesis of substituted isoquinolin-1-yl-2-(cycloalk2-enylidene)hydrazines and their antimicrobial properties. J. Chil. Chem. Soc. 2009; 54: 183-5.

7. Kostecka M. Synthesis of a new group of aliphatic hydrazide derivatives and the correlations between their molecular structure and biological activity. Molecules 2012; 17: 3560-73
8. Kaur R, Singh A, Budhlakoti P, Sanwal R. Synthesis, characteristization and antifungal activity of certain (E)-1-(1-(substitutedphenyl)ethylidene)-2-(6methylbenzo[d] thiazol-2-yl)hydrazine analogues. Int J. Pharm. Biol. Arch. 2010; 1:56-61.

9. Sechi M, Azeena U, Delussu MP, Dallochio R, Dessi A, Cosseddu A, Pala N, Neamati N. Design and synthesis of bis-amide and hydrazide containing derivatives of malonic acid as potential HIV-1 integrase inhibitors. Molecules 2008; 13: 2442-61.

10. Raparti V, Chitre T, Bothara K, Kumar V, Dangre S, Khachane C, Gore S, Deshmane B. Novel 4(morpholin-4-yl)-N'-(arylidene)benzohydrazides; synthesis, antimycobacterial activity and QSAR investigations. Eur. J. Med. Chem. 2009; 44: 395460 .

11. McMurry J. Organic Chemistry, $7^{\text {th }}$ Ed. Thomson Learning Inc. USA 2008; 877-84.

12. Habibi D, Marvi O. Montmorillonite KSF and montmorillonite K-10 clays as efficient catalysts for the solventless synthesis of bismaleimides and bisphthalimides using microwave irradiation. General paper Arkivoc (xiii) 2006: 8-15.

13. Jain AK, Gupta PK, Ganesan K, Pande A, Malhotra RC. Rapid solvent free synthesis of aromatic hydrazides under microwave irradiation. Defense Science Journal 2007; 57 (2): 267-70.

14. Balouri M., Sadiki M., Ibnsouda SK. Methods for in vitro evaluating antimicrobial activity: a review. Journal of Pharmaceutical Analysis, 2016; 11 (5), pp. 1-10.

15. Vellaiswamy G, Ramaswamy S. Synthesis, spectral characterization and antimicrobial screening of novel Schiff bases from sulfa drugs. International Journal of Pharmacy and Pharmaceutical Sciences, 2014; 6 (1): 487-91.

16. Namasivayam N, Theivarasu C. Synthesis of substituted piperidine-4-ones with dichloro(cyclooctadiene) palladium (II) and antimicrobial activity, International Journal of 
Suzana et al. / Synthesis of N'-(2-Methoxybenzylidene)...

Pharmacy and Pharmaceutical Sciences, 2014; 6 (1): 440-4.

17. Ramalingan C, Park YT, Kabilan S. Synthesis, stereochemistry and antimicrobial evaluation of substituted piperidin-4-one oxime ethers. Eur J Med Chem, 2006; 41: 683-96.

18. Kumar S, Goel N, Afzal O, Ali MR, Bawa S. In vitro antibacterial/antifungal screening of 2-chloroquinoline scaffold derivatives. Journal of Antibiotics Research, 2015; 1 (1):101. Kabalka GW, Wang I, Pagni RM Potassium fluoride doped alumina: an effective reagent for ester hydrolysis under solvent free conditions. Green Chemistry 2001; 3: 261-2.

19. Paul S, Nanda $P$ and Gupta R. PhCOCl$\mathrm{Py} /$ BasicAlumina as a versatile reagent for benzoylation in solvent-free condition. Molecule 2003; 8: 374-80.

20. Pavia DL, Gary M, Lampman, George S, Kriz, James RV. Introduction of Spectroscopy, $4^{\text {th }} \mathrm{Ed}$. Brooks/Cole USA 2009: 381-403.
21. Silverstein RM, Francis XW, David JK. Spectrometric Identification of Organic Compounds, $7^{\text {th }}$ Ed. John Wiley and Sons Inc. USA 2005; 72-4.

22. Kapoor M., Mukhi PLS., Surolia N., Kusuga K., Surolia A. Kinetic and structural analysis of the increased affinity of enoyl-ACP (acyl-carrier protein) reductase for triclosan in presence of $\mathrm{NAD}^{+}$. Biochemistry Journl, 2004; 381:725-733.

23. Meng E.C., Shoichet B.K., Kuntz I.D. Automated docking with grid-based energy evaluation. Journal of Computational Chemistry, 2004; 13 (4), pp. 505-524.

24. Merkl R., Hradkova L., Filip V., Smidrkal J. Antimicrobial and antioxidant properties of phenolic acids alkyl esters. Czech J. Food Sci., 2010; 28: 275279

25. Pangal A., Ahmed K., Shaikh S. Synthesis, Characterization and Study of Antimicrobial Activity of 2,6-Ditertiarybutyl-1,4-benzoquinone hydrazones International research Journal of Pharmacy, 2013; 4 (8), pp. 172-176 
Synthesis of N'-(2-Methoxybenzylidene)-4-Hydroxy Benzohydrazide and N'-(4-Nitrobenzylidene)-4-Hydroxy Benzohydrazide, in Silico Study and Antibacterial Activity

ORIGINALITY REPORT

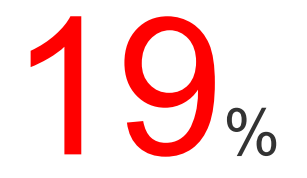

SIMILARITY INDEX

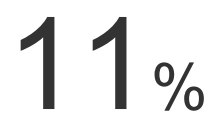

INTERNET SOURCES

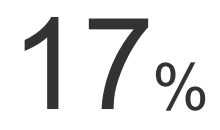

PUBLICATIONS
$0 \%$

STUDENT PAPERS

\section{PRIMARY SOURCES}

1

S Suzana, M I Sulistyowaty, Isnaeni, T Budiati.

"Synthesis, docking molecule study and antibacterial activity of N'-(4-

Fluorobenzylidene)-4- hydroxybenzohydrazide and N'-(4-Fluorobenzylidene)-4hydroxybenzohydrazide)", Journal of Physics:

Conference Series, 2019

Publication

2 www.ijppsjournal.com Internet Source

3 Tatsumi Kimura. "Branched epoxy copolymers with oligo(benzoate) side chains carrying donor and acceptor functions in each end", Polymers for Advanced Technologies, 03/2001

Publication

Kosuke Kuroda, Yumiko Shimada, Kenji

Takahashi. "Hand-holding and releasing between the anion and cation to change their macroscopic behavior in water", Green Energy 
\& Environment, 2019

Publication

5 onlinelibrary.wiley.com

Internet Source

6 Sanjaya, Ridwan, Agustine Eva Maria Soekesi,

and A. Posmaria Setiasiwi Sitohang.

"Technology entrepreneurship model

development for teachers", International

Journal of Technoentrepreneurship, 2015.

Publication

7 "Handbook of Computational Chemistry",

Springer Nature, 2017

$1 \%$

Publication

8 ijpbs.net

Internet Source

$9 \quad$ www.ajol.info

Internet Source

10 lib.ui.ac.id

Internet Source

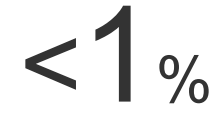

11 shodhganga.inflibnet.ac.in:8080

Internet Source

12 Sébastien Moniot, Mariantonietta Forgione,

Alessia Lucidi, Gebremedhin S. Hailu et al.

"Development of 1,2,4-Oxadiazoles as Potent and Selective Inhibitors of the Human 
Deacetylase Sirtuin 2: Structure-Activity

Relationship, X-ray Crystal Structure, and

Anticancer Activity", Journal of Medicinal

Chemistry, 2017

Publication

13 www.google.com

Internet Source

$<1 \%$

14 www.imedpub.com

Internet Source

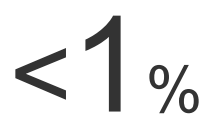

15 www.faqs.org

Internet Source

$<1 \%$

16 Jin, Hongjun, Jinda Fan, Xiang Zhang, Junfeng

Li, Hubert P. Flores, Joel S. Perlmutter, Stanley

$<1 \%$

M. Parsons, and Zhude Tu. "Radiosynthesis

and in vivo evaluation of a novel $\sigma 1$ selective

PET ligand", MedChemComm, 2014.

Publication

17 worldwidescience.org

Internet Source

18 Wang, C.. "Chlorotrimethylsilane-promoted

one-pot synthesis of steroidal[17,16-

d]pyrimidines", Steroids, 201012

Publication 
Exclude quotes

Off

Exclude matches

Off

Exclude bibliography

On 